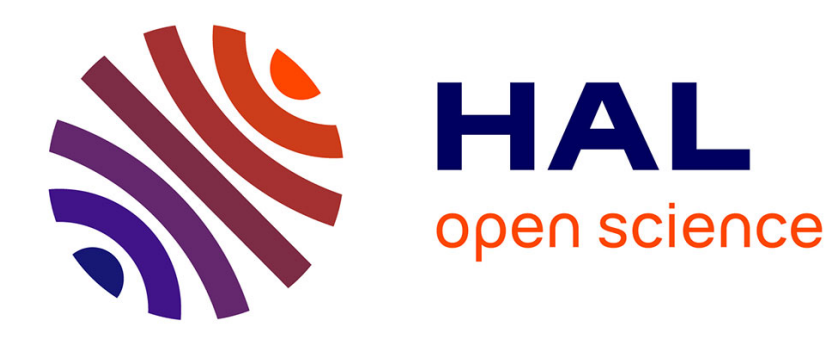

\title{
Thermochemistry and Reaction Mechanisms of Nitromethane Ignition
}

\author{
C. Melius
}

\section{To cite this version:}

C. Melius. Thermochemistry and Reaction Mechanisms of Nitromethane Ignition. Journal de Physique IV Proceedings, 1995, 05 (C4), pp.C4-535-C4-548. 10.1051/jp4:1995443 · jpa-00253749

\section{HAL Id: jpa-00253749 https://hal.science/jpa-00253749}

Submitted on 1 Jan 1995

HAL is a multi-disciplinary open access archive for the deposit and dissemination of scientific research documents, whether they are published or not. The documents may come from teaching and research institutions in France or abroad, or from public or private research centers.
L'archive ouverte pluridisciplinaire HAL, est destinée au dépôt et à la diffusion de documents scientifiques de niveau recherche, publiés ou non, émanant des établissements d'enseignement et de recherche français ou étrangers, des laboratoires publics ou privés. 
JOURNAL DE PHYSIQUE IV

Colloque C4, supplément au Journal de Physique III, Volume 5, mai 1995

\title{
Thermochemistry and Reaction Mechanisms of Nitromethane Ignition
}

\author{
C.F. Melius \\ Combustion Research Facility, Sandia National Laboratories, Livermore, CA 94551-0969, U.S.A.
}

\begin{abstract}
The thermochemistry and reaction mechanisms of nitromethane initiation are modeled using detailed chemical kinetics. Initial conditions correspond to gaseous nitromethane at atmospheric and liquid-like densities and initial temperatures between 1100 and $2000 \mathrm{~K}$. Global reactions as well as elementary reactions are identified for each of the two stages of ignition. The chemical steps to convert the nitro group to $\mathrm{N}_{2}$ involve a complex set of elementary reactions. The time-dependence of the ignition steps (ignition delay times) as a function of temperature and pressure is used to determine effective activation energies and pressure dependencies to ignition. The ignition delay times range from several nanoseconds to tens of microseconds. At atmospheric conditions, the delay times for both ignition stages are in excellent agreement with observed experimental data. At the high densities, the ignition times at these elevated temperatures appear to be dominated by the same reaction mechanism that occurs for atmospheric gaseous nitromethane initiation. This is to be contrasted with lower temperature, condensedphase ignition studies where it appears that solvent-assisted reactions dominate.
\end{abstract}

\section{INTRODUCTION}

The ability to identify the chemical reactions involved in the initiation of energetic materials is challenging due to the extremely short time scales involved as well as the high temperatures and pressures that are generated. Furthermore, the chemical intermediates of ignition are highly reactive. The chemistry of nitro compounds, such as nitramines and nitroaromatics, is further complicated by the fact that they may undergo two-stage ignition. We therefore have investigated the initiation of nitromethane as a prototype of an energetic material containing the nitro moiety. The ignition of nitromethane has been studied both experimentally [1-9 ] and computationally [1,10-15]. In particular, the ignition delay time of gas-phase ignition of nitromethane has been studied by Guirguis et al. [1] in which they were able to observe two stages of ignition. Several groups have modeled the ignition process using detailed chemical kinetics $[1,9]$, including previous work by us $[13,14]$. The modeling was able to treat the first-stage ignition reasonably well, but the second-stage ignition delay times were off by several orders of magnitude. Recent work by Lin and coworkers [16-18] have improved our understanding of the elementary reactions involving the $\mathrm{NO}, \mathrm{HNO}, \mathrm{NO}_{2}$, and $\mathrm{HCN}$ species. This has enabled us to generate an improved detailed reaction mechanism for nitromethane. We use this improved mechanism to study the initiation of gaseous nitromethane at atmospheric conditions as well as at densities corresponding to that of

*Work supported by the U. S. Department of Energy. 
liquid nitromethane. We present the thermodynamics and reaction pathways of the ignition steps. We then use the ignition delay times to determine effective activation energies and pressure dependencies.

\section{METHOD}

The study of ignition in a uniformly heated system, such as in a shock tube, allows us to study the combustion chemistry of energetic materials in a environment that can provide the initial decomposition and initiation reaction mechanisms. The energetic material can be treated as a homogeneous gas mixture in a closed system, in which we follow the time-dependent evolution of the chemical species. For instance, we can treat an adiabatic system with constant pressure or volume, or we can follow the chemistry under shock detonation conditions. We use the SENKIN program [19], which includes sensitivity analysis, for the integration of the energy and mass conservation equations.

In this section, we study the chemistry of gaseous nitromethane initiation. The ignition of nitromethane is treated as being under constant volume. The governing equations are $[14,19]$

$$
\frac{\mathrm{dY}}{\mathrm{dt}}=\mathrm{v} \dot{\omega}_{\mathrm{k}} \mathrm{W}_{\mathrm{k}}(\mathrm{k}=1, \ldots, \mathrm{K})
$$

and

$$
c_{\mathrm{v}} \frac{\mathrm{dT}}{\mathrm{dt}}=-\mathrm{v} \sum_{\mathrm{k}=1}^{\mathrm{K}} \mathrm{e}_{\mathrm{k}} \dot{\omega}_{\mathrm{k}} \mathrm{W}_{\mathrm{k}},
$$

In the above equations, $T$ is the temperature, $Y_{k}$ the mass fraction of the $\mathrm{k}^{\text {th }}$ species, $\mathrm{W}_{\mathrm{k}}$ is the molecular weight of the $k^{\text {th }}$ species, $t$ is time, $v=V / m$ is the specific volume, $e_{k}$ is the internal energy of the $\mathrm{k}^{\text {th }}$ species, $\mathrm{c}_{\mathrm{v}}$ is the constant volume heat capacity of the mixture, and $\dot{\omega}_{\mathrm{k}}$ is the molar rate of production of the $\mathrm{k}^{\text {th }}$ species. The chemical reaction mechanism included 48 species and 312 elementary reactions. The thermochemical dynamic properties and chemical production rates are evaluated using the Chemkin package [19]. The 48 species and their heats of formation are presented in Table I.

Table I. The chemical species used in the detailed chemical kinetic modeling of nitromethane.

\begin{tabular}{|c|c|c|c|c|}
\hline $\mathrm{CH}_{3} \mathrm{NO}_{2}$ & -16.84 & 2 & $\mathrm{CH}_{3} \mathrm{ONO}$ & -15.25 \\
\hline NO & 21.58 & 4 & $\mathrm{NO}_{2}$ & 7.91 \\
\hline HNO & 23.80 & 6 & HONO & -18.34 \\
\hline $\mathrm{N}_{2} \mathrm{O}$ & 19.61 & 8 & $\mathrm{H}$ & 52.10 \\
\hline $\mathrm{H}_{2}$ & 0.0 & 10 & $\mathrm{O}$ & 59.56 \\
\hline $\mathrm{O}_{2}$ & 0.0 & 12 & $\mathrm{OH}$ & 9.32 \\
\hline $\mathrm{H}_{2} \mathrm{O}$ & -57.8 & 14 & $\mathrm{HO}_{2}$ & 2.50 \\
\hline 15 & 112.96 & 16 & $\mathrm{~N}_{2}$ & 0.0 \\
\hline $\mathrm{NH}$ & 85.2 & 18 & $\mathrm{NH}_{2}$ & 45.50 \\
\hline $\mathrm{NH}_{3}$ & -11.97 & 20 & $\mathrm{NNH}$ & 58.57 \\
\hline HNNO & 55.20 & 22 & $\mathrm{HNOH}$ & 21.06 \\
\hline $\mathrm{H}_{2} \mathrm{NO}$ & 15.82 & 24 & $\mathrm{~N}_{2} \mathrm{H}_{2}$ & 50.90 \\
\hline $\mathrm{CO}$ & -26.42 & 26 & $\mathrm{CO}_{2}$ & -94.06 \\
\hline $\mathrm{HCO}$ & 10.40 & 28 & $\mathrm{CH}_{2} \mathrm{O}$ & -27.70 \\
\hline $\mathrm{CH}_{3} \mathrm{O}$ & 3.90 & 30 & $\mathrm{CH}_{2} \mathrm{OH}$ & -4.10 \\
\hline
\end{tabular}
Also given are the heats of formation at $298 \mathrm{~K}\left(\Delta \mathrm{H}_{\mathrm{f} 298}^{\mathrm{O}}\right)$, where energies are given in kcal-mol-1. 
Table I. (Cont.)

\begin{tabular}{|c|c|c|c|c|c|}
\hline 31 & $\mathrm{CH}_{3} \mathrm{OH}$ & -48.06 & 32 & $\mathrm{CH}_{3}$ & 34.82 \\
\hline 33 & $\mathrm{CH}_{4}$ & -17.90 & 34 & $\mathrm{CN}$ & 104.01 \\
\hline 35 & $\mathrm{HCN}$ & 31.89 & 36 & $\mathrm{H}_{2} \mathrm{CN}$ & 59.11 \\
\hline 37 & $\mathrm{CH}_{3} \mathrm{NH}$ & 44.94 & 38 & HCNO & 38.43 \\
\hline 39 & $\mathrm{HOCN}$ & -3.53 & 40 & $\mathrm{HNCO}$ & -28.22 \\
\hline 41 & $\mathrm{NCO}$ & 31.51 & 42 & $\mathrm{NCN}$ & 107.60 \\
\hline 43 & $\mathrm{CH}_{3} \mathrm{NO}$ & 18.95 & 44 & $\mathrm{H}_{2} \mathrm{CNO}_{2}$ & 36.47 \\
\hline 45 & $\mathrm{H}_{2} \mathrm{CNO}$ & 41.43 & 46 & $\mathrm{CH}_{3} \mathrm{NHO}$ & 13.32 \\
\hline 47 & $\mathrm{H}_{2} \mathrm{CNOH}$ & 5.15 & 48 & $\mathrm{CH}_{2} \mathrm{NO}_{2} \mathrm{H}$ & -2.86 \\
\hline
\end{tabular}

\section{RESULTS}

In Figs. 1 and 2, we present the temperature and species profiles as a function of time for the initiation of 100 per cent gaseous $\mathrm{CH}_{3} \mathrm{NO}_{2}$ at 7.25 atmospheres and $1131 \mathrm{~K}$. These conditions are representative of the experimental conditions of Guirguis et al. [1]. The initiation undergoes two ignition stages, at $13.3 \mu \mathrm{sec}$ and $25.8 \mu \mathrm{sec}$, respectively. The final temperature is $3598 \mathrm{~K}$.

The chemistry can be subdivided by time into several stages: (I) a preliminary stage of slow decomposition followed by (II) a first-stage ignition that undergoes a rapid temperature rise followed by (III) an intermediate stage in which the temperature remains on a plateau followed by (IV) a second-stage ignition where the temperature again rises rapidly to form the final products. The reaction mechanism flow diagrams for the first-stage ignition (II), the intermediate stage (III), and the second-stage ignition (IV) are shown in Figs. 3-5. These reaction pathways show the dominating elementary reactions occurring in each of these stages, with thick arrows being the major pathways while thin arrows are the minor pathways. We have separately shown the reaction chemistry for the carbon atom and the nitrogen atom of nitromethane. The carbon atom must be oxidized, to form $\mathrm{CO}$ and, to a lesser extent, $\mathrm{CO}_{2}$ (note that there is not enough oxygen in nitromethane to oxidize the carbon to $\mathrm{CO}_{2}$ and the hydrogen to $\mathrm{H}_{2} \mathrm{O}$ ). Meanwhile, the nitrogen, which is in an oxidized state as part of the nitro group moiety, must be reduced to $\mathrm{N}_{2}$. The reaction flow diagram for the preliminary decomposition stage (I) is similar to that of the first-stage ignition (II) and thus is not shown. The major difference is that the preliminary stage (I) occurs at the low end of the temperature range, giving rise to slower rates and resulting in a greater variety of minor intermediate species being formed.

In Figs. 6-8, we show the enthalpies and free energies of possible species corresponding to the composition $\mathrm{C}_{1} \mathrm{H}_{3} \mathrm{~N}_{1} \mathrm{O}_{2}$. This represents the composition of nitromethane and includes tautomers of nitromethane as well as various product species. Besides the $\Delta \mathrm{H}$ at $300 \mathrm{~K}$ (see Table I for individual species heats of formation), we present the $\Delta \mathrm{G}^{\prime} \mathrm{s}$ at $300 \mathrm{~K}$ and $2000 \mathrm{~K}$.

Fig. 1 showed the time profile for nitromethane initiation at 7.25 atmospheres and $1131 \mathrm{~K}$, indicating two rapid temperature rises at $13.6 \mu \mathrm{sec}$ and $26.1 \mu \mathrm{sec}$, designated $\tau_{1}$ and $\tau_{2}$ respectively. In Table II, we present these ignition delay times, $\tau_{1}$ and $\tau_{2}$, for various initial temperatures and pressures. These results are used to determine activation energies of ignition, defined by the relation $\ln \left(\tau_{\mathrm{a}} / \tau_{\mathrm{b}}\right) \propto(\Delta \mathrm{E} / \mathrm{R})\left(1 / \mathrm{T}_{\mathrm{a}}-1 / \mathrm{T}_{\mathrm{b}}\right)$. The resulting $\Delta \mathrm{E}$ 's for the first-stage and second-stage ignitions are presented in Table III. In a similar manner, we can define pressure dependencies to the ignition delay time by the relation $\ln \left(\tau_{\mathrm{a}} / \tau_{\mathrm{b}}\right) \propto \mathrm{n} \ln \left(\mathrm{P}_{\mathrm{a}} / \mathrm{P}_{\mathrm{b}}\right)$, which corresponds to $\tau$ being proportional to $\mathrm{P}^{\mathrm{n}}$. The resulting pressure exponents are given in Table IV. 


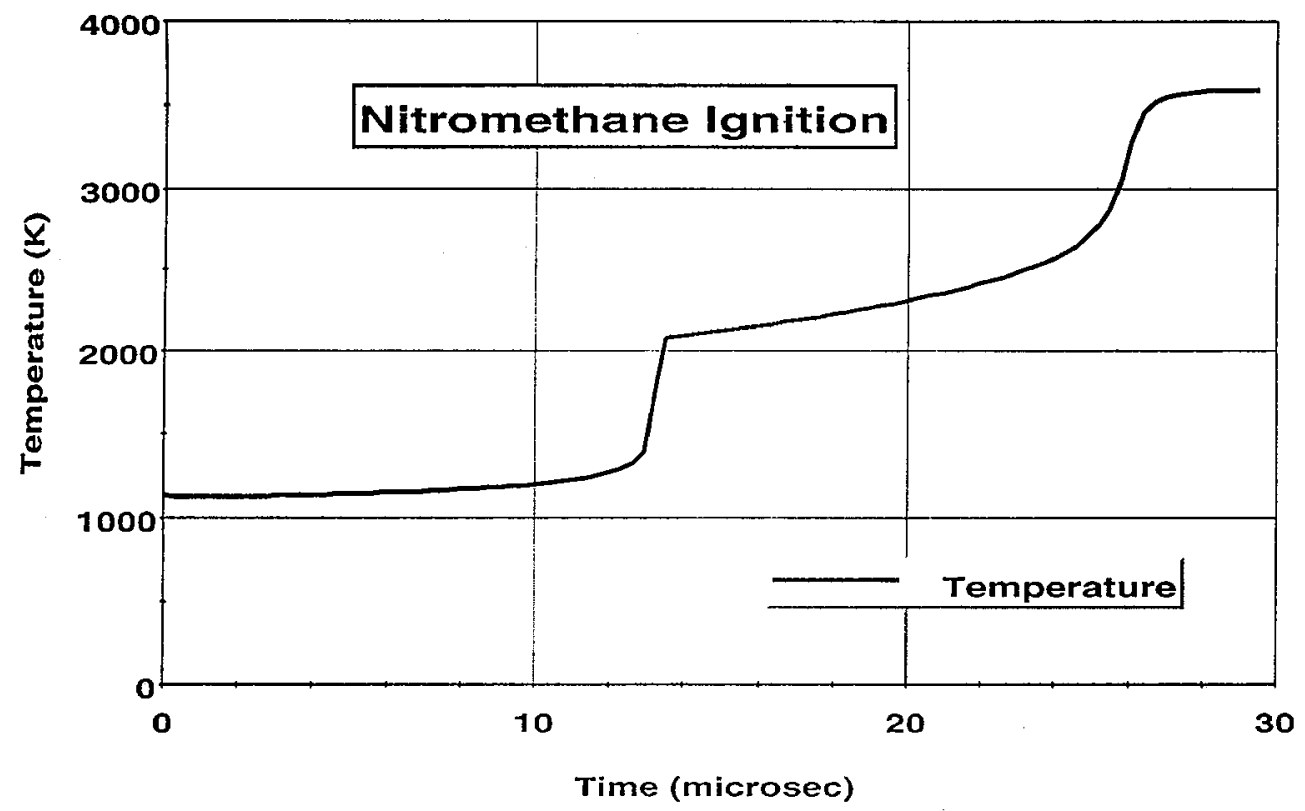

Fig. 1. Temperature vs. time profile for ignition of nitromethane. Initial conditions are $1131 \mathrm{~K}$ and $7.25 \mathrm{~atm}$.

\section{Species Concentration}

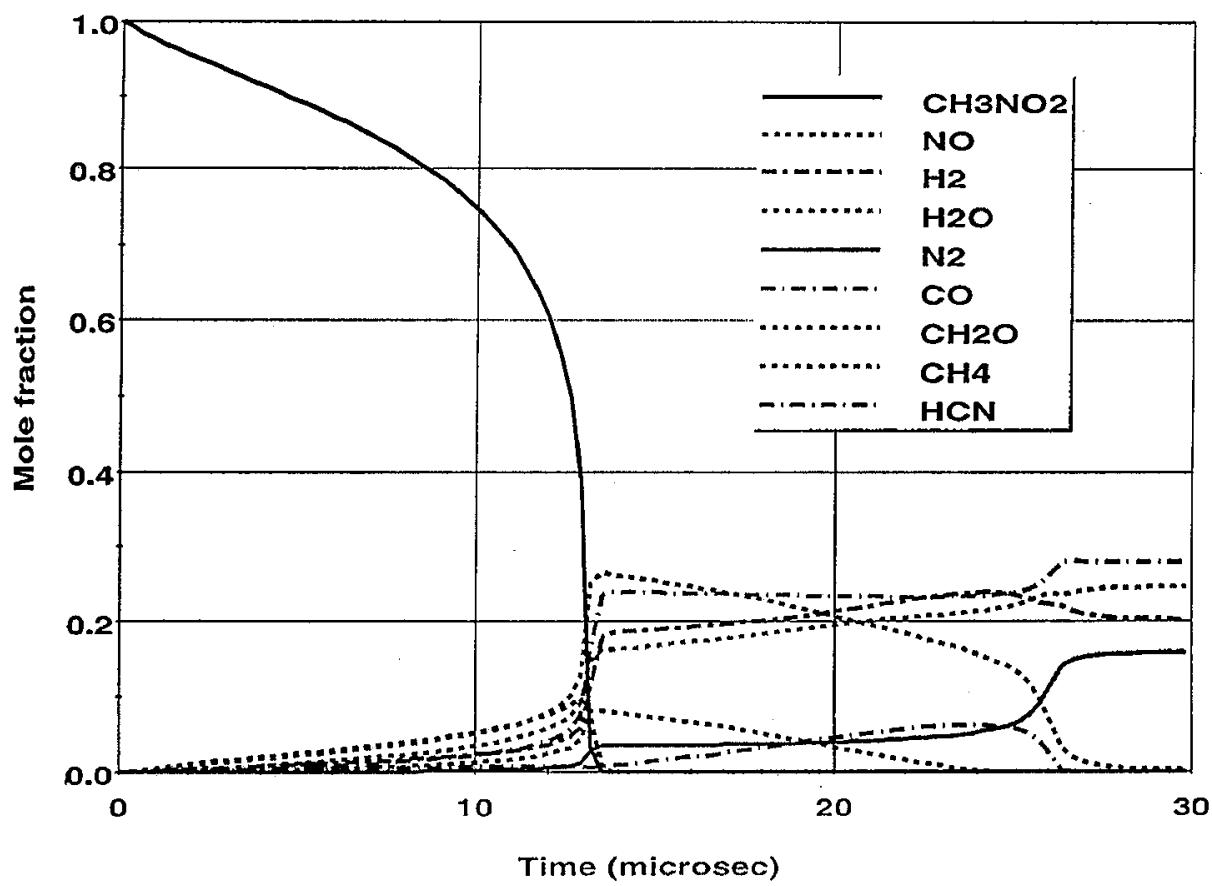

Fig. 2. Species vs. time profile for ignition of nitromethane. Intial conditions are $1131 \mathrm{~K}$ and 7.25 atm. 


\section{Nitromethane First Stage Ignition Chemistry}

\section{Carbon Mechanism}

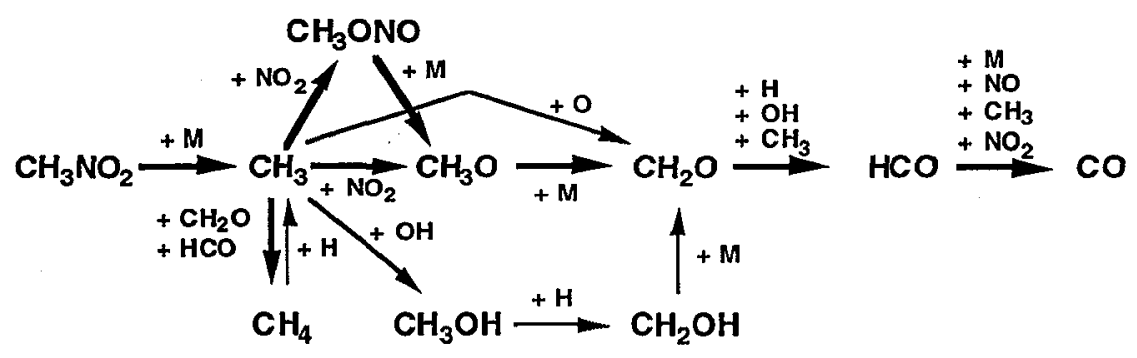

Nitrogen Mechanism

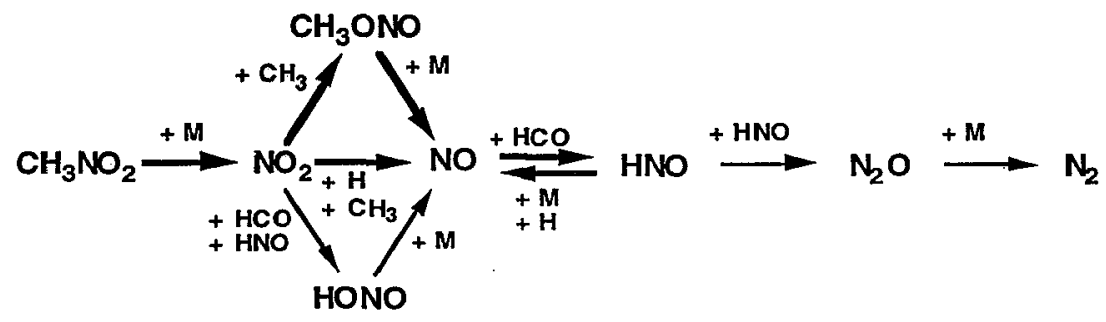

Fig. 3. Reaction mechanism flow diagrams for the first stage-ignition of nitromethane. Thick arrows indicate major pathways. Dominant collision partners for bimolecular reactions are indicated next to arrows. Unimolecular decomposition reactions are indicated by the third-body notation $+M$. The chemistry of carbon- and nitrogen-containing species are presented separately.

\section{Nitromethane Intermediate Stage Chemistry}

\section{Carbon Mechanism}

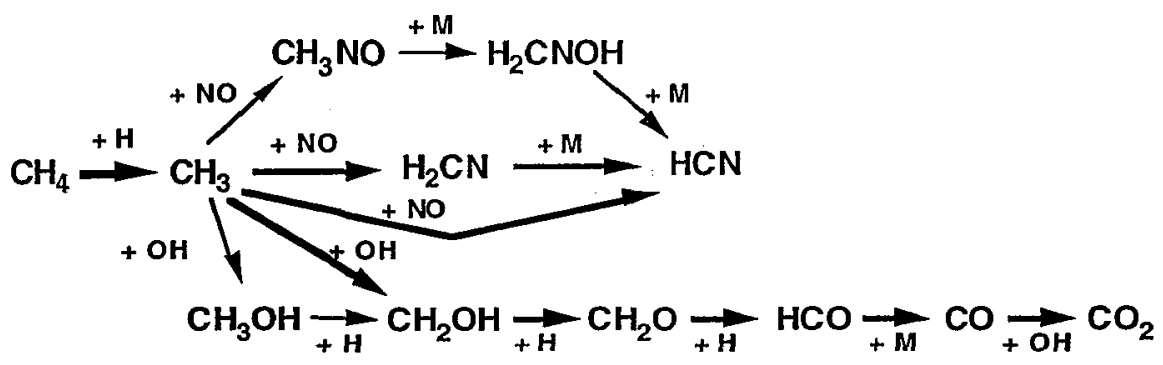

Nitrogen Mechanis m

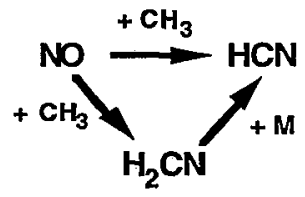

Fig. 4. Reaction mechanism flow diagrams for the intermediate stage (between first- and secondstage) ignition of nitromethane. See Fig. 3 for further caption descriptions. 


\section{Nitromethane Second Stage Ignition Chemistry}

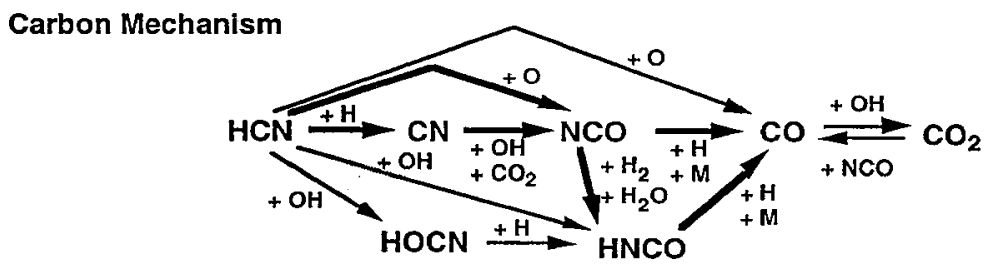

Nitrogen Mechanism from HCN

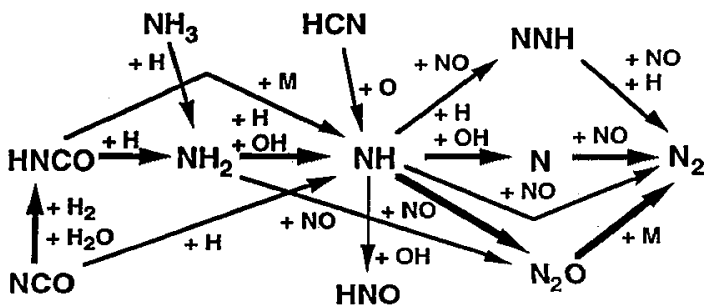

Nitrogen Mechanism from NO

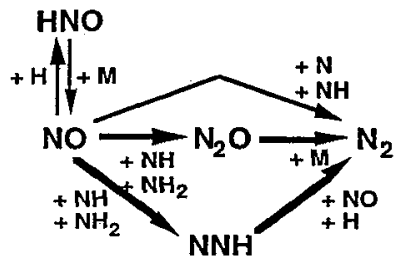

Fig. 5. Reaction mechanism flow diagrams for the second-stage ignition of nitromethane. See Fig. 3 for further caption descriptions.

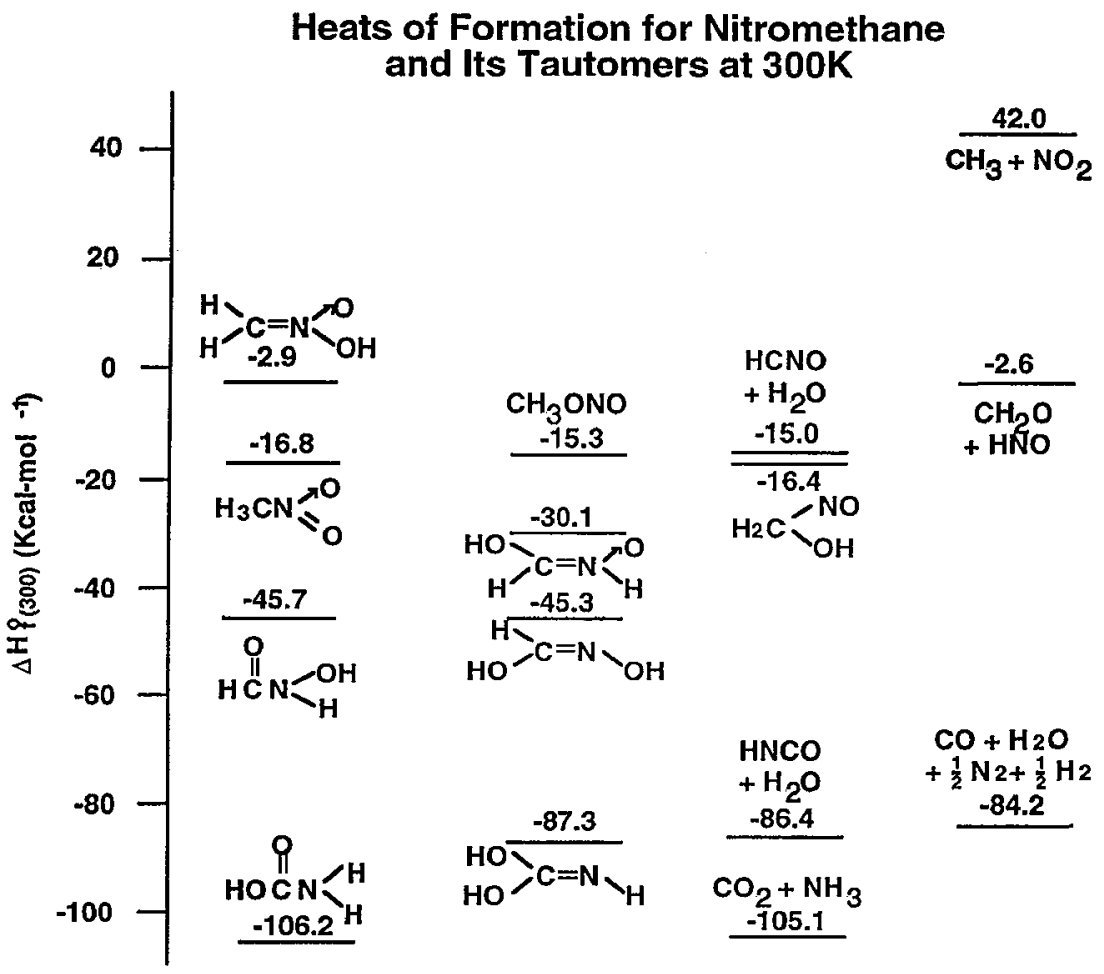

Fig. 6. Heats of formation, $\Delta \mathrm{H}$ 's, at $300 \mathrm{~K}$ for nitromethane and its tautomers and other stoichiometric products. Enthalpies are in kcal-mol ${ }^{-1}$. 


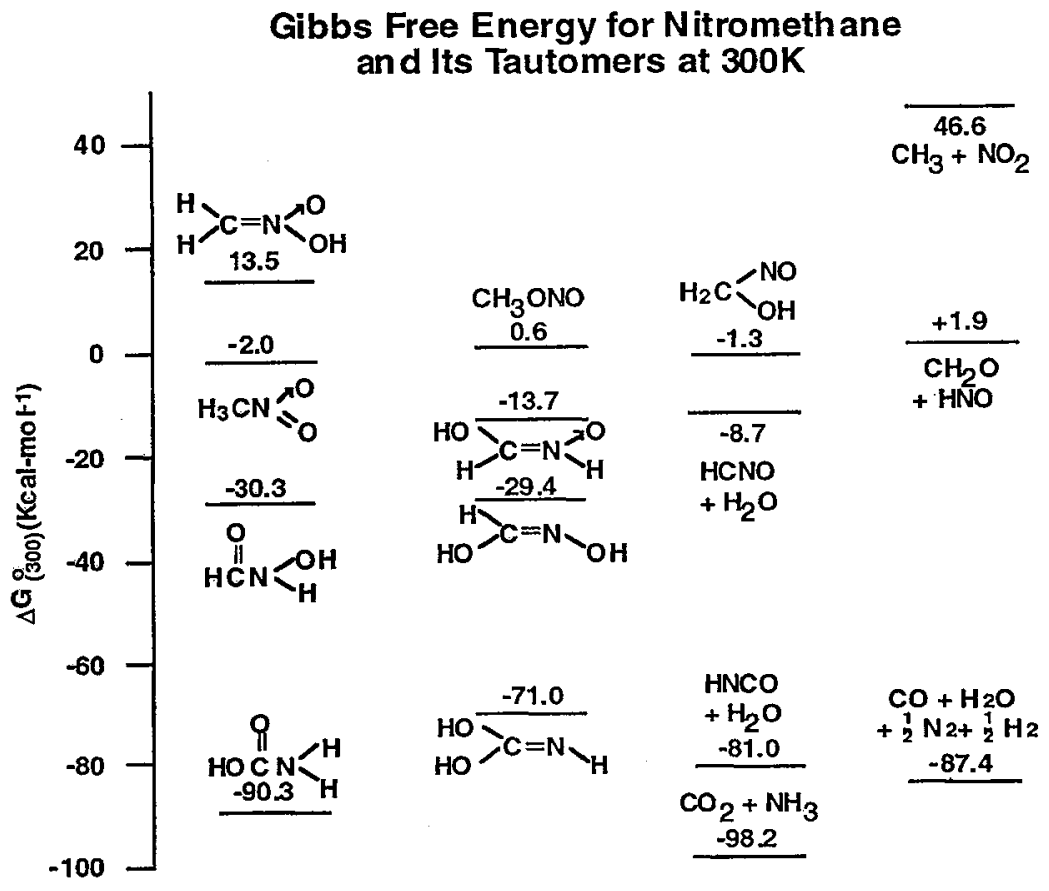

Fig. 7. Free energies, $\Delta \mathrm{G}$ 's, at $300 \mathrm{~K}$ for nitromethane and its tautomers and other stoichiometric products. Free energies are in $\mathrm{kcal}_{-\mathrm{mol}^{-1}}$.

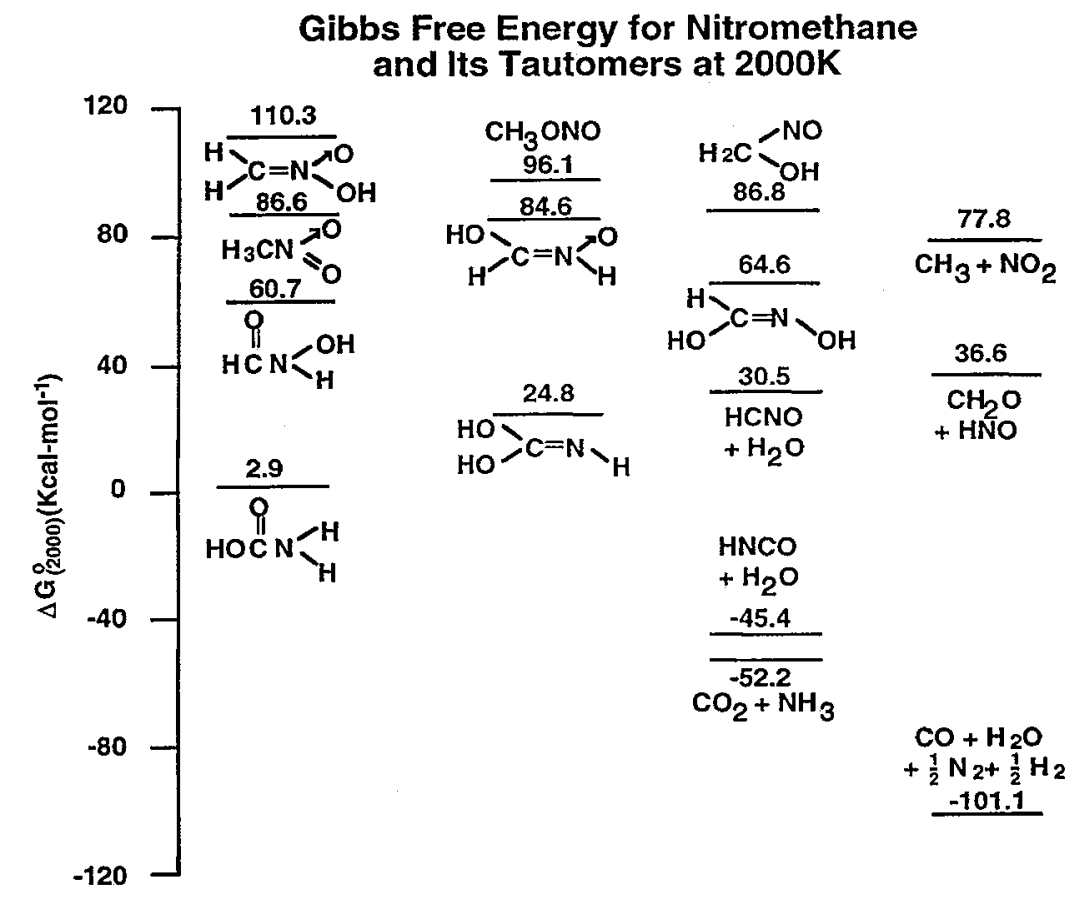

Fig. 8. Free energies, $\Delta G^{\prime}$ s, at $2000 \mathrm{~K}$ for nitromethane and its tautomers and other stoichiometric products. Free energies are in $\mathrm{kcal}^{-\mathrm{mol}^{-1}}$. 
Table II. Ignition delay times for gaseous nitromethane for different initial temperatures and pressures.

$\begin{array}{lrccc}\mathrm{T}(\mathrm{K}) & \mathrm{P}(\mathrm{Atm}) & \tau_{1} & \tau_{2} & \tau_{2}-\tau_{1} \\ 1131 & 5.25 & 14.9 \mu \mathrm{s} & 35.5 \mu \mathrm{s} & 20.6 \mu \mathrm{s} \\ 1131 & 7.25 & 13.3 \mu \mathrm{s} & 25.8 \mu \mathrm{s} & 12.5 \mu \mathrm{s} \\ 1331 & 5.25 & 1.6 \mu \mathrm{s} & 25.3 \mu \mathrm{s} & 23.7 \mu \mathrm{s} \\ 1331 & 7.25 & 1.2 \mu \mathrm{s} & 15.5 \mu \mathrm{s} & 14.3 \mu \mathrm{s} \\ 1331 & 8.53 & 1.2 \mu \mathrm{s} & 12.3 \mu \mathrm{s} & 11.1 \mu \mathrm{s} \\ 1131 & 1574.4 & 4.352 \mu \mathrm{s} & 4.403 \mu \mathrm{s} & .051 \mu \mathrm{s} \\ 1131 & 1852.8 & 4.288 \mu \mathrm{s} & 4.298 \mu \mathrm{s} & .010 \mu \mathrm{s} \\ 1331 & 1574.4 & 0.208 \mu \mathrm{s} & 0.219 \mu \mathrm{s} & .010 \mu \mathrm{s} \\ 1331 & 1852.8 & 0.202 \mu \mathrm{s} & 0.208 \mu \mathrm{s} & .006 \mu \mathrm{s} \\ 1900 & 2644.8 & 2.52 \mathrm{~ns} & 4.76 \mathrm{~ns} & 2.24 \mathrm{~ns} \\ 2000 & 2784 \mathrm{~ns} & 1.59 \mathrm{~ns} & 3.59 \mathrm{~ns} & 2.00 \mathrm{~ns}\end{array}$

Table III. Activation energies of ignition (defined by $\ln \left(\tau_{\mathrm{a}} / \tau_{\mathrm{b}}\right) \propto \Delta \mathrm{E} / \mathrm{R}\left(1 / \mathrm{T}_{\mathrm{a}}-1 / \mathrm{T}_{\mathrm{b}}\right)$ ). Ignition delay times are taken from Table II. Energies in kcal-mol-1.

$\begin{array}{clllr}\text { Constant Pressure } & \mathrm{T}(\mathrm{K}) & \mathrm{P}(\mathrm{Atm}) & \Delta \mathrm{E}_{1} & \Delta \mathrm{E}_{2} \\ 1230 & 5.25 & 33.2 & 7.6 \\ 1230 & 7.25 & 35.6 & 5.1 \\ 1230 & 1574.4 & 45.4 & 44.9 \\ 1230 & 1852.8 & 45.7 & 45.3 \\ \text { Constant Volume } & \mathrm{T}(\mathrm{K}) & \mathrm{P}(\mathrm{Atm}) & \Delta \mathrm{E}_{1} & \Delta \mathrm{E}_{2} \\ & 1230 & 5.25 & 35.7 & 11.0 \\ & 1230 & 1574.4 & 45.9 & 45.6 \\ & 1950 & 2644.8 & 34.8 & 21.3\end{array}$


Table IV. Pressure dependence of ignition delay times for gaseous nitromethane. Pressure dependence is defined by $\tau \propto \mathrm{Pn}$ or $\ln \left(\tau_{\mathrm{a}} / \tau_{\mathrm{b}}\right) \propto \mathrm{n} \ln \left(\mathrm{P}_{\mathrm{a}} / \mathrm{P}_{\mathrm{b}}\right)$. Ignition delay times are taken from Table $I$.

Low Pressure

Low to High

High Pressure

\section{DICUSSION}

\subsection{Chemical Reactions}

Several points regarding the nitromethane thermochemistry can be observed from Figs. 6-8. First, from the $\Delta H$ 's presented in Fig. 6 , it is seen that indeed nitromethane is an unstable tautomer of $\mathrm{C}_{1} \mathrm{H}_{3} \mathrm{~N}_{1} \mathrm{O}_{2}$, lying $\sim 90 \mathrm{kcal}^{-\mathrm{mol}^{-1}}$ above the most stable form, $\mathrm{C}(\mathrm{O}) \mathrm{OHNH}_{2}$. In fact, $\mathrm{C}(\mathrm{O}) \mathrm{OHNH} \mathrm{H}_{2}$ is more stable than the major products of detonation, $\mathrm{CO}, \mathrm{H}_{2} \mathrm{O}, \mathrm{N}_{2}$, and $\mathrm{H}_{2}$ (see Fig. 2).

Furthermore, as can be seen in Fig. 6, the lowest bond-breaking moiety for $\mathrm{CH}_{3} \mathrm{NO}_{2}$ is the breaking of the $\mathrm{C}-\mathrm{N}$ bond to form $\mathrm{CH}_{3}+\mathrm{NO}_{2}$. which is endothermic by nearly 59 kcal-mol. ${ }^{-1}$ Thus, from an enthalpy view point, $\mathrm{CH}_{3} \mathrm{NO}_{2}$ would appear to be a reasonable energetic material.

However, while one tends to think of the thermochemistry of the reactions in terms of enthalpies (e.g., heats of reaction), it is the free energy of the system that drives the reaction. Dividing the $\mathrm{C}_{1} \mathrm{H}_{3} \mathrm{~N}_{1} \mathrm{O}_{2}$ molecular species into two or more species lowers the free energy, particularly at higher temperatures. As one can see from Fig. 8, at $2000 \mathrm{~K}$, the $\Delta \mathrm{G}$ of $\mathrm{CH}_{3}+\mathrm{NO}_{2}$ is more stable than that of $\mathrm{CH}_{3} \mathrm{NO}_{2}$ itself. And the breakup of $\mathrm{CH}_{3} \mathrm{NO}_{2}$ into its small product molecules, $\mathrm{CO}$, $\mathrm{H}_{2} \mathrm{O}, \mathrm{N}_{2}$, and $\mathrm{H}_{2}$, forming three molecules from one reactant molecule is extremely exothermic. Thus, it is necessary to have more than the thermostability to bond breaking to make an insensitive energetic material. As we shall see, it is necessary to have a reaction pathway which prevents direct conversion of the energetic material to products.

The overall reaction chemistry converting nitromethane to products is

$$
\mathrm{CH}_{3} \mathrm{NO}_{2} \rightarrow \mathrm{CO}+1 / 2 \mathrm{~N}_{2}+\mathrm{H}_{2} \mathrm{O}+1 / 2 \mathrm{H}_{2} \quad \Delta \mathrm{H}_{\mathrm{Rxn}}=-67
$$

with minor contributions of the following reactions

$$
\begin{array}{lll}
\mathrm{CO}+\mathrm{H}_{2} \mathrm{O} \rightarrow \mathrm{CO}_{2}+\mathrm{H}_{2} & (1 / 10) & \Delta \mathrm{H}_{\mathrm{Rxn}}=-10 \\
\mathrm{H}_{2} \mathrm{O} \rightarrow \mathrm{H}+\mathrm{OH} & (1 / 15) & \Delta \mathrm{H}_{\mathrm{Rxn}}=+119 \\
\mathrm{H}_{2} \rightarrow \mathrm{H}+\mathrm{H} & (1 / 30) & \Delta \mathrm{H}_{\mathrm{Rxn}}=+104
\end{array}
$$


Contributions of R2-R4 relative to reaction $\mathrm{R} 1$ are given in parentheses. The heats of reaction $\Delta \mathrm{H}_{\mathrm{Rxn}}$ are given in $\mathrm{kcal}-\mathrm{mol}^{-1}$.

As stated above, the chemistry can be subdivided by time into several stages: (I) a preliminary stage of slow decomposition followed by (II) a first-stage ignition that undergoes a rapid temperature rise followed by (III) an intermediate stage in which the temperature remains on a plateau followed by (IV) a second-stage ignition where the temperature again rises rapidly forming the final products. This temporal division of chemical reactions, as indicated in Fig. 2, is consistent with the temporal division of the temperature into a preliminary, first-stage ignition, intermediate region, and second-stage ignition, as indicated in Fig. 1. The reaction chemistry during the preliminary stage (I) is

$$
\begin{gathered}
9 \mathrm{CH}_{3} \mathrm{NO}_{2} \rightarrow 5 \mathrm{CH}_{2} \mathrm{O}+5 / 8 \mathrm{HNO}+7 / 4 \mathrm{CO}+35 / 8 \mathrm{NO}+5 / 2 \mathrm{H}_{2}+3 \mathrm{H}_{2} \mathrm{O}+3 / 4 \mathrm{~N}_{2} \mathrm{O} \\
+\mathrm{HCN}+\mathrm{CH}_{4}+5 / 8 \mathrm{NO}_{2}+1 / 4 \mathrm{CO}_{2}+1 / 4 \mathrm{~N}_{2}+3 / 8 \mathrm{HONO} \quad \Delta \mathrm{H}_{\mathrm{Rxn}}=-10
\end{gathered}
$$

the reaction during the first-stage ignition (II) is

$$
4 \mathrm{CH}_{3} \mathrm{NO}_{2} \rightarrow 3 \mathrm{CO}+\mathrm{CH}_{4}+3 \mathrm{NO}+1 / 2 \mathrm{~N}_{2}+2 \mathrm{H}_{2}+2 \mathrm{H}_{2} \mathrm{O} \quad \Delta \mathrm{H}_{\mathrm{Rxn}}=-20,
$$

the reaction during the intermediate-stage ignition (III) between the first- and second-stage ignitions is

$$
4 \mathrm{CH}_{4}+6 \mathrm{NO}+\mathrm{CO} \rightarrow 4 \mathrm{HCN}+5 \mathrm{H}_{2} \mathrm{O}+\mathrm{H}_{2}+\mathrm{N}_{2}+\mathrm{CO}_{2} \quad \Delta \mathrm{H}_{\mathrm{Rxn}}=-48,
$$

while the reaction during the second-stage ignition (IV) is

$$
\begin{aligned}
& 7 \mathrm{HCN}+13 \mathrm{NO}+5 / 2 \mathrm{H}_{2} \rightarrow 6 \mathrm{CO}+10 \mathrm{~N}_{2}+\mathrm{CO}_{2}+3 \mathrm{H}_{2} \mathrm{O} \\
& +2 \mathrm{OH}+4 \mathrm{H}
\end{aligned}
$$$$
\Delta \mathrm{H}_{\mathrm{Rxn}}=-54 .
$$

In order to relate the heats of reaction, $\Delta \mathrm{H}_{\mathrm{Rxn}}$, of the individual reactions to each other, we have normalized the $\Delta \mathrm{H}_{\mathrm{Rxn}}$ for each of the reactions to the $\mathrm{CH}_{3} \mathrm{NO}_{2}$ molecule. Thus, the $\Delta \mathrm{H}_{\mathrm{Rxn}}$ 's are normalized per $\mathrm{CH}_{3} \mathrm{NO}_{2}$ (R5 and R6) or $\mathrm{NO}$ (R7 and R8) molecule.

The global reactions for each stage in the nitromethane initiation can be further subdivided into subglobal reactions which begin to indicate the reaction mechanism of each stage. While this reaction subdivision is not unique, we have attempted to define those subglobal reactions which represent simple combinations of elementary reactions, as indicated in Figs. 3-5. In addition to the subglobal reaction, we also indicate the relative contribution of each reaction to the net reactions presented above. We also give the absolute heat of reaction, $\Delta H_{R \times n}$, for each of the subglobal reactions.

The preliminary stage (I) global reaction R5 is composed of the subglobal reactions

$$
\begin{aligned}
& \mathrm{CH}_{3} \mathrm{NO}_{2} \rightarrow \mathrm{CH}_{2} \mathrm{O}+\mathrm{HNO} \\
& \mathrm{CH}_{3} \mathrm{NO}_{2} \rightarrow \mathrm{CO}+\mathrm{NO}+3 / 2 \mathrm{H}_{2} \\
& 2 \mathrm{CH}_{3} \mathrm{NO}_{2} \rightarrow \mathrm{CH}+\mathrm{CO}+\mathrm{H}_{2}+\mathrm{NO}+\mathrm{NO}_{2} \\
& 2 \mathrm{CH}_{3} \mathrm{NO}_{2}+\mathrm{HNO} \rightarrow \mathrm{HCN}+\mathrm{CH}_{2} \mathrm{O}+2 \mathrm{H}_{2} \mathrm{O}+2 \mathrm{NO} \\
& 2 \mathrm{HNO}_{2} \mathrm{~N}_{2} \mathrm{O}+\mathrm{H}_{2} \mathrm{O} \\
& \mathrm{NO}_{2}+\mathrm{HNO} \rightarrow \mathrm{HONO}+\mathrm{NO} \\
& \mathrm{CO}+2 \mathrm{HNO} \rightarrow \mathrm{CO}_{2}+\mathrm{N}_{2}+\mathrm{H}_{2} \mathrm{O}
\end{aligned}
$$

$$
\begin{aligned}
& \Delta H_{\mathrm{Rxn}}=+13 \\
& \Delta \mathrm{H}_{\mathrm{Rxn}}=+12 \\
& \Delta \mathrm{H}_{\mathrm{Rxn}}=+19 \\
& \Delta \mathrm{H}_{\mathrm{Rxn}}=-58 \\
& \Delta \mathrm{H}_{\mathrm{Rxn}}=-85 \\
& \Delta \mathrm{H}_{\mathrm{Rxn}}=-28 \\
& \Delta \mathrm{H}_{\mathrm{Rxn}}=-173 .
\end{aligned}
$$

The first-stage global reaction R6 is composed of the subglobal reactions

$$
\begin{aligned}
& \mathrm{CH}_{3} \mathrm{NO}_{2} \rightarrow \mathrm{CO}+\mathrm{NO}+3 / 2 \mathrm{H}_{2} \\
& \mathrm{CH}_{3} \mathrm{NO}_{2}+3 / 2 \mathrm{H}_{2} \rightarrow \mathrm{CH}_{4}+\mathrm{NO}+\mathrm{H}_{2} \mathrm{O}
\end{aligned}
$$

$$
\begin{aligned}
& \Delta H_{\mathrm{Rxn}}=+12 \\
& \Delta \mathrm{H}_{\mathrm{Rxn}}=-37
\end{aligned}
$$


The intermediate-stage global reaction $\mathrm{R} 7$ is composed of the subglobal reactions

$$
\begin{aligned}
& \mathrm{CH}_{4}+\mathrm{NO} \rightarrow \mathrm{HCN}+\mathrm{H}_{2} \mathrm{O}+1 / 2 \mathrm{H}_{2} \\
& \mathrm{H}_{2}+\mathrm{NO} \rightarrow \mathrm{H}_{2} \mathrm{O}+1 / 2 \mathrm{~N}_{2} \\
& \mathrm{CO}+\mathrm{H}_{2} \mathrm{O} \rightarrow \mathrm{CO}_{2}+\mathrm{H}_{2}
\end{aligned}
$$

$$
\begin{aligned}
& \Delta H_{\mathrm{Rxn}}=-30 \\
& \Delta \mathrm{H}_{\mathrm{Rxn}}=-79 \\
& \Delta \mathrm{H}_{\mathrm{Rxn}}=-10 .
\end{aligned}
$$

The second-stage global reaction $\mathrm{R} 8$ is composed of the subglobal reactions

$$
\begin{aligned}
& \mathrm{HCN}+\mathrm{NO} \rightarrow \mathrm{CO}+\mathrm{N}_{2}+1 / 2 \mathrm{H}_{2} \\
& \mathrm{CO}+\mathrm{H}_{2} \mathrm{O} \rightarrow \mathrm{CO}_{2}+\mathrm{H}_{2} \\
& \mathrm{H}_{2}+2 \mathrm{NO} \rightarrow \mathrm{N}_{2}+2 \mathrm{OH} \\
& \mathrm{OH}+\mathrm{H}_{2} \rightarrow \mathrm{H}_{2} \mathrm{O}+\mathrm{H}
\end{aligned}
$$

$$
\begin{aligned}
& \Delta H_{\text {Rxn }}=-80 \\
& \Delta H_{\text {Rxn }}=-10 \\
& \Delta H_{\text {Rxn }}=-25 \\
& \Delta H_{\text {Rxn }}=-15 .
\end{aligned}
$$

The net result of the preliminary (I) and first-stage ignition (II) reactions steps is the conversion of the $\mathrm{NO}_{2}$ moiety to NO. During the preliminary stage (I), the decomposition of $\mathrm{CH}_{3} \mathrm{NO}_{2}$ is only slightly exothermic. In fact, the dominant decomposition reaction R5a is endothermic. Subsequent reactions involving the HNO species provide the exothermic heat release. The first-stage ignition (II) chemistry is slightly more exothermic. However, the major exothermic heat release of initiation arises during the second-stage ignition chemistry.

The net result of the intermediate (III) and second-stage ignition (IV) reactions is the conversion of $\mathrm{NO}$ to $\mathrm{N}_{2}$. The $\mathrm{NO}$ to $\mathrm{N}_{2}$ conversion does not occur readily and requires the presence of hydrogen and $\mathrm{HCN}$. The formation of $\mathrm{HCN}$ occurs primarily during the intermediate stage (III). This stage (III), which removes the $\mathrm{CH}_{4}$, is also exothermic but slow. The rapid reaction rates of the second-stage ignition are a result of the high temperatures.

While the net reaction is conversion of $\mathrm{CH}_{3} \mathrm{NO}_{2}$ to $\mathrm{CO}, \mathrm{H}_{2} \mathrm{O}, \mathrm{N}_{2}$, and $\mathrm{H}_{2}$, the overall chemical process of ignition is complicated. Many steps are required to form the final exothermic products. The chemistry can be divided into two major efforts, (1) conversion of the $\mathrm{NO}_{2}$ moiety to $\mathrm{NO}$ and (2) conversion of the NO moiety to $\mathrm{N}_{2}$. This process is generic to all nitro-containing energetic materials, including nitrate esters and nitramines [14]. The result is two separated ignition stages, denoted the first or primary stage and the secondary stage.

The primary-stage ignition is conversion of the $\mathrm{NO}_{2}$ to $\mathrm{NO}$. This can be written stoichiometrically as $\mathrm{CH}_{3} \mathrm{NO}_{2} \rightarrow \mathrm{CO}+\mathrm{NO}+3 / 2 \mathrm{H}_{2}$. Note that this reaction is itself endothermic (see reaction R6a). On the other hand, three and a half molecules are formed for each nitromethane molecule, so the entropy of this reaction if favorable, leading to a favorable free energy of reaction as the temperature increases. In order to gain heat release, some of the NO must be reduced. In the preliminary stage (I), $\mathrm{N}_{2} \mathrm{O}$ is formed via the $\mathrm{HNO}$ intermediate. During the first-stage ignition (II), the temperature rise is sufficient to allow thermal decomposition of the $\mathrm{N}_{2} \mathrm{O}$ to form $\mathrm{N}_{2}$. The relative importance of $\mathrm{CH}_{4}$ and $\mathrm{CH}_{3} \mathrm{OH}$ has changed from our previous investigation [14], with $\mathrm{CH}_{4}$ now playing the more significant role. The relative importance of $\mathrm{CH}_{4}$ to $\mathrm{CH}_{3} \mathrm{OH}$ is extremely sensitive to the pressure dependence used for various elementary rate constants. In both cases, these species serve to create a temporary heat source (see reaction $\mathrm{R} 6 \mathrm{~b}$ ). The formation of $\mathrm{CH}_{4}$ occurs earlier in the reaction mechanism (arising from $\mathrm{CH}_{3}$ ) than does formation of $\mathrm{CH}_{3} \mathrm{OH}$ (arising from $\mathrm{CH}_{3} \mathrm{O}$ as indicated in ref. 14).

One can see from Fig. 3 that even the oxidation of the carbon of nitromethane to CO is a multistep process. The major pathway has the $\mathrm{CH}_{3} \mathrm{NO}_{2}$ breaking the $\mathrm{C}-\mathrm{N}$ bond to form $\mathrm{CH}_{3}+\mathrm{NO}_{2}$ which recombines to form $\mathrm{CH}_{3} \mathrm{ONO}$ which breaks the $\mathrm{O}-\mathrm{N}$ bond to form $\mathrm{CH}_{3} \mathrm{O}+\mathrm{NO}$. The $\mathrm{NO}$ then abstracts the $\mathrm{H}$ from $\mathrm{CH}_{3} \mathrm{O}$ to form $\mathrm{CH}_{2} \mathrm{O}+\mathrm{HNO}$. Subsequent abstraction of hydrogen atoms 
from $\mathrm{CH}_{2} \mathrm{O}$ lead to $\mathrm{CO}$. As one can see from Figs. 6-8, this series of reactions is itself endothermic. Thus, the initial set of reactions do not produce significant heat release. This complex set of reactions plays an important role in keeping the nitro compounds from spontaneously decomposing. The heat release from any exothermic reactions is converted into net endothermic reactions. These series of elementary reactions are necessary to move the oxygen atom from the nitrogen atom to the carbon atom, which cannot occur until the $\mathrm{C}-\mathrm{N}$ bond is first broken.

The secondary stage ignition is the reduction of $\mathrm{NO}$ to $\mathrm{N}_{2}$. This occurs by first reducing one of the nitrogen atoms to a reduced state in HCN. This reduced nitrogen is then oxidized with another oxidized nitrogen of $\mathrm{NO}$ to form the formally neutral $\mathrm{N}_{2}$. The formation of the reduced state of nitrogen, HCN, occurs during the intermediate stage (III). This step is necessary because the NO molecule is very stable, even at the intermediate temperatures.

As noted above, the large free energy release of the reaction is enhanced by the net increase in the entropy of the reaction. The majority of this entropy increase occurs during the preliminary and first-stage ignition, where the decomposition of each nitromethane molecule leads to between two and three new molecules. Thus, while the exothermicity of the preliminary and first stages of the reaction are small compared to that of the intermediate and second stages, the increase in entropy plays an important role in driving the initiation process, allowing the initial reactions to proceed.

\subsection{Ignition Delay Times}

As discussed in the above section on the reaction mechanism, the nitromethane molecule cannot "spontaneously" decompose to form exothermic products but rather must undergo a series of intermediate steps, many of which are endothermic. These reactions lead to finite ignition delay times, both for the primary and secondary stages. We can analyze these ignition delay times, $\tau_{1}$ and $\tau_{2}$, in terms of energies of activation, $\Delta E_{1}$ and $\Delta E_{2}$, and pressure dependencies $n_{1}$ and $n_{2}$, as defined above and in Tables II-IV. The $\Delta E^{\prime}$ 's and $n_{i}$ 's are define as derivatives of the ignition delay times $\tau_{\mathrm{i}}$ 's with respect to temperature and pressure, respectively, and thus, have meaning only in the near region of the temperature and pressure specified. We have calculated the ignition delay times for atmospheric pressures as well as a high pressure range corresponding to a nitromethane density of that of liquid nitromethane. The pressure values presented in Tables II-IV are an idealized gas effective pressure with the real gas pressure being much higher. For the constant volume calculations, it is better to view the calculations as constant density calculations.

The atmospheric conditions match the experimental data of Guirguis et al. [1]. The ignition delay times are in quite good agreement with the experimental data. The $7.25 \mathrm{~atm}, 1131 \mathrm{~K}$ conditions, for which the experimental was able to separate the two ignition stages, yielded a $\tau_{1}$ and a $\tau_{2}$ of 13.3 and $25.8 \mu \mathrm{sec}$, which are in remarkable agreement with the experimental data of $\sim 12$ and $\sim 25$ $\mu$ sec respectively. These results give us confidence that the elementary reactions for modeling nitromethane are accurate. This represents an improvement over the reaction mechanism used previously [14], which had a reasonable first-stage ignition but a much delayed second stage ignition. The ignition delay times range from microseconds at the low pressure to hundreds of nanoseconds in the high density regime. At the high temperatures and densities, the $\tau_{1}$ 's approach the nanosecond time scale.

The effective activation energies of ignition are presented in Table III. The resulting $\Delta E$ 's indicate that the first-stage ignition has an activation energy $\Delta \mathrm{E}_{1}$ of $-33-36 \mathrm{kcal}-\mathrm{mol}^{-1}$ at atmospheric pressures, consistent with the experimental data [1]. At high densities, the $\Delta \mathrm{E}_{1}$ is larger, $\sim 46$ kcal-mol,,$^{-1}$ though at elevated temperatures $(1950 \mathrm{~K})$, the $\Delta \mathrm{E}_{1}$ is $\sim 35 \mathrm{kcal}-\mathrm{mol}^{-1}$ These large activation energies are dominated by the initial $\mathrm{C}-\mathrm{N}$ bond breaking process, which has a bond dissociation energy of $59 \mathrm{kcal}^{-m o l}-^{-1}$ The second-stage ignition delay times, $\tau_{2}$ 's, show a wide variation in activation energies. This occurs because the $\tau_{2}$ 's decrease significantly faster than the $\tau_{1}$ 's with increasing temperature and pressure. Ultimately, the $\tau_{2}$ 's approach the $\tau_{1}$ 's and are 
dominated by the $\tau_{1}$ times at high densities. However, the difference between the two stages, $\tau_{2}$ $\tau_{1}$, is still several nanoseconds (see Table II).

The effective pressure dependencies of ignition (at constant temperature) are presented in Table IV. The resulting $n_{i}$ 's exhibit varied behavior. At low temperature and pressure, the first-stage $n_{1}$ pressure dependence is between zeroth order $\left(n_{1}=0\right)$ and first order $\left(n_{2}=1\right)$, corresponding to effective unimolecular and bimolecular behavior. The secondary stage $n_{2}$ pressure dependence at the low temperature and pressure is first order and greater. At high pressures, both the $n_{1}$ and $n_{2}$ pressure dependencies approach zeroth order, indicating the dominance of the first-stage ignition delay time and the high effective activation energy representative of $\mathrm{C}-\mathrm{N}$ bond breaking. It is difficult to relate these pressure dependencies to shock induced experiments where temperature changes occur simultaneously with pressure changes.

The comparison of our high density results with the experimental ignition delay times at kilobar pressures and low temperatures indicate some significant differences. As an example, we use the experimental ignition delay times measured by Lee et al. [3] for 10 and $50 \mathrm{kbar}$ and 400-600 K. Their $\tau$ 's range from $10-100$ seconds and have an effective activation energy of $\sim 16 \mathrm{kcal}-\mathrm{mol} .^{-1}$ While this activation energy is significantly lower than what we calculate for the higher

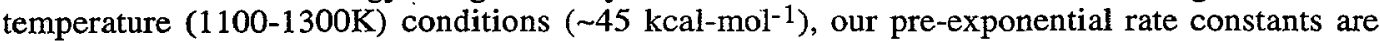
much larger. Defining the rate constant $\mathrm{k}$ as the inverse of the ignition delay time, the effective high temperature rate constant is $\mathrm{k}_{\mathrm{g}}=1.410^{14} \exp (-45.4 / \mathrm{RT})$ while the effective low temperature rate constant (at $10 \mathrm{kbar}$ ) is $2.710^{4} \exp (-15.7 / \mathrm{RT})$. That is, our ignition delay times are between $200 \mathrm{nsec}-4 \mu \mathrm{sec}$ while their extrapolated $\tau$ 's are still longer than $100 \mu \mathrm{sec}$. On the other hand, our $\tau$ 's in the $400-600 \mathrm{~K}$ range would be longer than theirs. This suggests a switch in mechanism in which at the lower temperatures, the reaction mechanism is "condensed phase"-like, involving proton transfer and hydrolysis reactions, while at high temperatures above $1000 \mathrm{~K}$, the reaction mechanism is "gas phase"-like, involving radical species. We have investigated the inclusion of bimolecular as well as solvent-assisted proton transfer and hydrolysis reactions in our mechanism to mimic the condensed phase reaction process. The results are encouraging. The small preexponential rate constants for such reactions (possessing severe entropy constraints) make such reactions important in the 400-600 K temperature range while they have essentially no effect in the $1100-1900 \mathrm{~K}$ range. Considerable work remains in order to elucidate the actual elementary reactions for the low temperature, condensed-phase regime.

\section{CONCLUSIONS}

We have calculated the initiation process for nitromethane using detailed chemical kinetics. The starting conditions were gaseous nitromethane at atmospheric pressures as well as elevated pressures corresponding to liquid density and temperature above $1000 \mathrm{~K}$. The results indicate that the chemical reaction mechanism requires multiple steps, in which many of the initial steps are endothermic. This complex chemical mechanism prevents the energetic nitro-compound from releasing its stored chemical energy immediately as a shock wave passes by. Ignition delay times indicate relatively high activation energies and low pressure dependencies, indicative of initial bond-breaking of the $\mathrm{C}-\mathrm{N}$ bond. The agreement between our ignition delay times and the experimental data of Guirguis et al. [1] is encouraging for the modeling of other nitro-containing energetic material. These systems will have similar $\mathrm{NO}, \mathrm{HNO}, \mathrm{N}_{2} \mathrm{O}$, and $\mathrm{HCN}$ chemistry, particularly for the second-stage ignition. These results indicate that a different mechanism is occurring at elevated temperatures $(>1000 \mathrm{~K})$ compared to lower temperatures.

\section{REFERENCES}

[1] R. Guirguis, D. Hsu, D. Bogan, and E. Oran, Comb. and Flames 61, 51 (1985).

[2] D. S. Y. Hsu and M. C. Lin, J. Ener. Mat., 3. 95 (1985).

[3] E. L. Lee, R. H. Sanborn, and H. D. Stromberg, Proc. 5th Symp. (Int) Detonation, 331 (1970).

[4] G. J. Piermarini, S. Block, and P. J. Miller, J. Phys. Chem. 93, 457 (1989). 
[5] C. P. Constantinou, T. Mukundan, and M. M. Chaudhri, Phil. Trans. R. Soc. Lond A $\underline{339}, 403$ (1992).

[6] J. Connor, Chemistry and Physics of the Molecular Processes in Energetic Materials (S. N. Bulusu, ed.), ASI 309, p 545 (1990).

[7] J. C. Mialocq, J. de Phys. C4, 163 (1987).

[8] S. Zeman, Thermochemica Acta, in press.

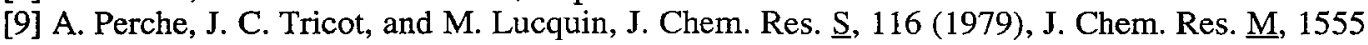
(1979).

[10] R. D. Bardo, $8^{\text {th }}$ Symp. (Int) Detonation, 855 (1989).

[11] M. D. Cook and P. J. Haskins, 12 th Int Pyro Symp., 43 (1987).

[12] S. Odiot, J. de Phys. C4, 225 (1987).

[13] C. F. Melius, Phil. Trans. R. Soc. Lond A 339 , 377 (1992).

[14] C. F. Melius, Chemistry and Physics of the Molecular Processes in Energetic Materials (S. N. Bulusu, ed.), ASI $\underline{309}$, p51 (1990).

[15] C. F. Melius, Chemistry and Physics of the Molecular Processes in Energetic Materials (S. N. Bulusu, ed.), ASI 309, p21 (1990).

[16] C.-Y. Lin, H.-T. Wang, M. C. Lin, and C. F. Melius, Int'l. J. Chem. Kinetics 22, 455 (1990).

[17] M. C. Lin, Y. He, and C. F. Melius, Int'l. J. Chem. Kinetics 24, 489 (1992).

[18] M. C. Lin, Y. He, and C. F. Melius, Int'l. J. Chem. Kinetics 24, 1103 (1992).

[19] A. E. Lutz, R. J. Kee, and J. A. Miller, Sandia Report SAND87-8248 (1987). 